\title{
Tribute to Professor Dr Enno Freerksen and Dr Harold Wheate
}

One of the reasons of this Symposium is that the German Leprosy Relief Association wants to pay tribute to Professor Dr Enno Freerksen who may be 
considered as a real pioneer of the development of new and effective drug regimens against leprosy. He paved the way for new approaches and developments without which this Symposium would not take place.

On the occasion of its General Assembly in November 1985 the German Leprosy Relief Association already honoured Professor Freerksen in an official way. I should like to seize the opportunity now to express to him once more the heartfelt thanks and deep appreciation of our association and of leprosy patients all over the world.

We also wish to pay tribute to a good and old friend of our association. In consideration of his long and outstanding engagement in leprosy work and his fruitful work as the Secretary to the Medical Commission of ILEP, the German Leprosy Relief Association thankfully bestows this document to Dr Harold Wheate. 